\title{
Endocrine Profile and Reproductive Performance in Heifers Induced to Lactation
}

\author{
Gabriela Bueno Luz', Andressa Stein Maffi', Eduardo Gularte Xavier', \\ Marcio Nunes Correa', Bernardo Garziera Gasperin ${ }^{3}$ \& Cassio Cassal Brauner ${ }^{1}$
}

\begin{abstract}
Background: Low reproductive efficiency has been one of the main factors that lead to dairy herd culling in the reproductive age. In multiparous animals, such inefficiency and culling can occur because of various factors and may be associated with occasional endocrine failures. To avoid revenue losses that incur due to lack of lactation, lactation is artificially induced in the animals that are not pregnant, using a defined protocol. The aim of this study was, therefore, to evaluate and compare the reproductive performance of heifers submitted to the induction protocol with that of pregnant heifers during the transition period.

Materials, Methods \& Results: Sixty Holstein heifers, $32 \pm 0.6$ months of age, were divided into two groups: Control Group (Control, $\mathrm{n}=30$ ) comprising pregnant heifers that were accompanied since 21 days before the expected calving date until 224 days in milk (DIM) and an Induction Group (Induction, $\mathrm{n}=30$ ) comprising non-pregnant heifers submitted to a lactation induction protocol, accompanied from the beginning of the protocol until 224 DIM. For evaluation of the endocrine profile (progesterone and estradiol concentrations) of these animals, blood samples were collected at two periods: the pre-lactation (weeks $-3,-2$ and -1) and post-lactation (weeks 1 and 4). Heifers from both groups were submitted to weekly reproductive evaluations, from the beginning of lactation until 35 DIM. Uterine examinations were performed using ultrasonography and vaginoscopy to evaluate uterine content, cervical opening, and mucosal aspect. Females in good reproductive health were subjected to a hormonal protocol for timed artificial insemination (TAI). The pregnancy rate of heifers that could reproduce (Control, $\mathrm{n}=13$, and Induction, $\mathrm{n}=20$ ) were evaluated and inseminated until 49 DIM. Progesterone levels were similar $(P>0.05)$ in the two groups at both pre- and post-start of lactation. Estradiol concentrations were different $(P<0.01)$ among groups only in the pre-lactation period. Higher levels of progesterone $(P=0.06)$ were observed in the induced heifers (Induction Group $=1.07 \pm 0.23 \mathrm{ng} / \mathrm{mL}$ and Control Group $=0.38 \pm 0.28 \mathrm{ng} / \mathrm{mL}$ ). Therefore, in the fourth week, induced heifers exhibited higher luteinic activity, the progesterone concentration was above $1 \mathrm{ng} / \mathrm{mL}$ in $42 \%$ of the animals, while just $12.5 \%$ of the Control heifers had it. The overall pregnancy rate was $47.75 \%$. The pregnancy rate recorded for induced heifers and Control heifers was $40 \%$ and $55.55 \%$, respectively.

Discussion: Progesterone and estradiol evaluations were performed in the first week after the beginning of the lactation to evaluate the metabolism and physiological concentration of the hormones used during the protocol. The measurements were again performed in the fourth week to evaluate the return to cyclicity of the heifers in both groups. The high serum concentrations of estradiol attained during the induction, in the pre-lactation period, may have possible interfered with the uterine environment and follicular population of these animals. Furthermore, it is possible that the hormonal combination used has a central effect on the synthesis and release of gonadotrophins and/or an effect on the ovarian follicular population. Based on the hormonal profile evaluated, particularly the endocrine profile, and the reproductive performance of heifers, the results suggest that the protocol for induced lactation has a positive effect on fertility.
\end{abstract}

Keywords: dairy cattle, estradiol, fertility, fixed-time artificial insemination, progesterone.

${ }^{1}$ Núcleo de Pesquisa, Ensino e Extensão em Pecuária \& ${ }^{3}$ Núcleo de Pesquisa e Ensino em Reprodução Animal (REPROPEL), Universidade Federal de Pelotas (UFPel), Pelotas, RS, Brazil. ${ }^{2}$ Granjas 4 Irmãos S.A., Rio Grande, RS. CORRESPONDENCE: C.C. Brauner [cassiocb@ gmail.com - Tel.: +55 (53) 32757136]. Departamento de Zootecnia, Faculdade de Agronomia Eliseu Maciel, UFPel. Campus Universitário s/n. CEP 96010-900 Capão do Leão, RS, Brazil. 


\section{INTRODUCTION}

In the last decades, the genetic selection of dairy cows for high milk yield has been associated with a marked decline in fertility [1]. Failures in reproductive efficiency have been one of the main factors underlying dairy herd culling during productive age [7]. In multiparous heifers, that inefficiency and culling may be associated with occasional endocrine failures. An alternative management protocol used to avoid discards and losses is induced lactation, based on the application of specific hormones (estradiol, progesterone, prostaglandin and cortisol) for 21 days [3]. Making it possible to simulate the hormone levels of the final gestation period, causing milk production without becoming pregnant.

Previous studies have evaluated reproductive parameters after induced lactation and reported satisfactory results, with improvements in fertility, and pregnancy rates varying from $41.4 \%$ to $71 \%$ during the induced lactation $[3,6]$. However, there is, limited information referring to the endocrinology of the animals submitted to the protocol and the mechanisms involved remain poorly understood.

In pregnant females, the hormonal physiological adaptations that occur during the transition period from a pregnant and non-lactant to non-pregnant and lactant status is well established [4]. However, in induced females few and outdated studies have addressed these questions. Therefore, the aim of this study was to evaluate the reproductive performance of heifers submitted to the protocol of induced lactation compared to pregnant heifers during the transition period.

\section{MATERIALS AND METHODS}

\section{Experimental design and treatments}

Sixty Holstein heifers, averaging $32 \pm 0.6$ months of age and body condition score between 3-3.5 ( 1 = emaciated, 5 = obese), were selected and allocated into two groups: control group (Control, $\mathrm{n}=30$ ) of pregnant heifers, evaluated from 21 days prepartum to 224 days in milk (DIM); and induced group (Induced, $\mathrm{n}=30$ ) comprising non-pregnant heifers, submitted to an artificial induction of lactation protocol. Before the protocol, heifers in the Induced group were presynchronized with two prostaglandin injections (11 days apart) to ensure that all the animals were at the same stage of the estrous cycle, and under the similar hormonal conditions. From the 1st to the 8th day, 30 mg of estradiol benzoate $\left(\text { Sincrodiol }{ }^{\circledR}\right)^{1}$ were administered daily, together with $300 \mathrm{mg}$ of progesterone $\left(\text { Sincrogest }{ }^{\circledR}\right)^{1}$. From the 9 th until the 14 th, animals only received daily doses of $20 \mathrm{mg}$ estradiol benzoate. On the 16th day, $0.56 \mathrm{mg}$ of sodium cloprostenol $\left(\text { Sincrocio }^{\circledR}\right)^{1}$ was administered and injections of 40 mg of dexamethasone sodium (Cortiflan $\left.{ }^{\circledR}\right)^{1}$ phosphate were administered daily from the $19^{\text {th }}$ to the $21^{\text {st }}$ day. On the $1^{\text {st }}, 8^{\text {th }}, 15^{\text {th }}$ and $22^{\text {nd }}$ day the animals received a dose of $500 \mathrm{mg}$ of sometribove zinc $\left(\text { Lactotropin }^{\circledR}\right)^{2}$. On the $22^{\text {nd }}$ day, milking began, twice a day until 224 DIM. Table 1 shows the diet composition of the daily rations for both groups in the 21 days before lactation and during lactation.

Table 1. Nutrient composition of daily rations for Control and Induction groups 21 days before lactation and during lactation.

\begin{tabular}{ccc}
\hline Component & 21 days pre-lactation & Lactation \\
\hline $\begin{array}{c}\text { Dry Matter (DM), kg } \\
\text { Net energy of lactation } \\
\text { (NEL), MJ }\end{array}$ & 49.4 & 49.6 \\
$\begin{array}{c}\text { Crude protein (CP), } \\
\text { \% DM }\end{array}$ & 1.53 & 1.68 \\
$\quad$ Fat, \% DM & 14.96 & 15.75 \\
$\begin{array}{c}\text { Neutral detergent fiber } \\
\text { (NDF), \% DM }\end{array}$ & 2.46 & 3.41 \\
DCAD (meq/100 g) & 43.26 & 35.74 \\
\hline
\end{tabular}

\section{Reproductive evaluations}

Heifers from both groups were submitted to weekly reproductive evaluations, from the beginning of lactation until 35 DIM. Uterine examinations were performed using ultrasonography and vaginoscopy to evaluate uterine content, cervical opening, and mucosal aspect. Animals from both groups were eligible for breeding after a 42-d voluntary waiting period. Heifers were considered to have good reproductive potential when they had adequate body corporal score $(\geq 3)$, uterine involution (Control Group), translucent mucus, and overall good health. Cows in adequate reproductive condition were subject to a hormonal protocol for timed artificial insemination (TAI) (Figure 1). Examinations with an ultrasound (7.5 - MHz, Mindray M5VET $®)^{3}$ with transrectal linear probe were performed for the diagnosis of pregnancy at 35 days after TAI. Cows that were not considered to have good reproductive potential until 42 DIM were subject to the conventional reproductive management of the farm. 


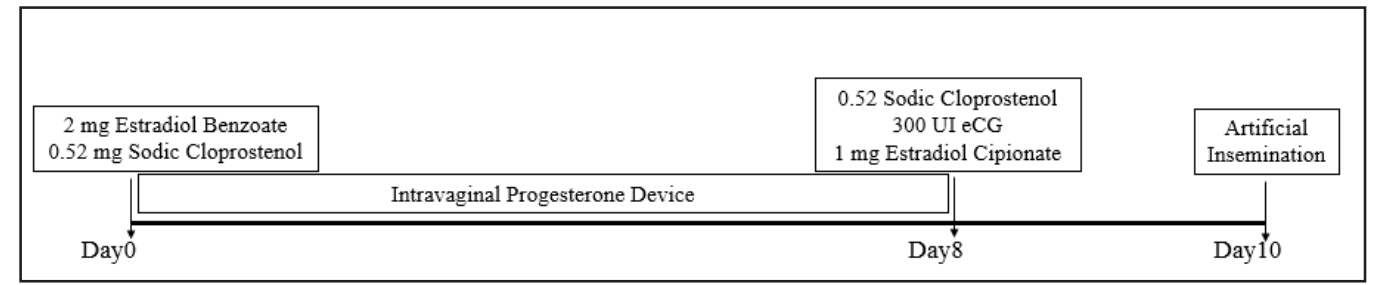

Figure 1. Protocol of timed artificial insemination used with females considered suitable for reproduction.

Blood sampling and analysis of hormonal profile

In both groups, weekly blood collections were performed from 21 days before the beginning of lactation (weeks: $-3,-2$, and -1) and in the first and fourth week of lactation (week 1 and 4). Blood was collected from the coccygeal arteriovenous complex using a vacutainer system, into tubes without anticoagulant for posterior evaluation of the estradiol and progesterone levels. Immediately after blood collection, the samples were centrifuged, processed, and frozen $\left(-20^{\circ} \mathrm{C}\right)$ in microtubes until further analysis. These analyses were performed by chemiluminescence using the Access ${ }^{2}$ Immunoassay System ${ }^{\circledR}{ }^{4}$ with specific kits.

\section{Statistical analysis}

Hormonal data were analyzed as repeated measures in a completely randomized design, considering the main effects of group (Control and Induced) over time (e.g., week -3, -2, -1; 1 and 4) and an effect of cow. The following statistical model was analyzed via Repeated Measurements ANOVA of NCSS 2004 and PASS 2005 (NCSS and PASS. Number Cruncher Statistical Systems. Kaysville, Utah):

$$
\mathrm{Y}_{\mathrm{ijkl}}=\mu+\mathrm{M}_{\mathrm{j}}+\mathrm{T}_{\mathrm{k}}+\mathrm{M}_{\mathrm{T} \mathrm{jk}}+\mathrm{c}_{\mathrm{l}}\left(\mathrm{b}_{\mathrm{i}}\right)+\mathrm{e}_{\mathrm{ijk} \mathrm{l}} \text {, }
$$

where: $Y_{\mathrm{ijkl}}$ is the dependent continuous variable, $\mu$ is the overall mean, $M_{j}$ is fixed effect of group $(j=$ Control vs. Induced), $\mathrm{T}_{\mathrm{k}}$ is the fixed effect of time (weeks), $M_{\text {Tjk }}$ is the interaction between group and time, $c_{1}\left(b_{i}\right)$ is the random effect of cow, and $e_{i j k l}$ is the random residual error.

Reproductive performance data consisted of pregnancy rate and the interval of calving-toconception (Control group) or beginning of lactationto-conception (Induced group). Analysis of frequency was utilized for the pregnancy rate considering data from animals breed until 42 DIM. Significance was considered at $P \leq 0.05$, and trends were considered at $P>0.06$ to $P \leq 0.10$.

\section{RESULTS}

Progesterone levels were similar $(P>0.05)$ during both pre- and post-start of lactation among groups. At week -2, induced heifers had a peak of progesterone levels (from $4.4 \pm 1.5 \mathrm{ng} / \mathrm{mL}$ at week -3 to $14.14 \pm 1.5$ $\mathrm{ng} / \mathrm{mL}$ at week -2$)[P<0.001]$ (Figure 2). Control heifers, showed a continuous decline until parturition, with a more marked decline in the last prepartum week $(6.08 \pm 1.50$ $\mathrm{ng} / \mathrm{mL}$ to $0.01 \pm 0.41 \mathrm{ng} / \mathrm{mL}$ in the first week postpartum).

Estradiol concentrations showed significant differences $(P<0.01)$ among groups only in the prelactation period, because induced heifers had increased estradiol levels during the first two weeks. In the first week (-3) before the beginning of the protocol, the average basal level of estradiol for induced heifers was $46.2 \mathrm{pg} / \mathrm{mL}$, which increased to $1246.6 \mathrm{pg} / \mathrm{mL}$ after ten days of daily injections. Heifers of the control group, in the same period, had concentrations ranging from $93.0 \mathrm{pg} / \mathrm{mL}$ (week -3) to $75.8 \mathrm{pg} / \mathrm{mL}$ (week -2).

During the lactation period, no differences were found between the groups or between weeks $(P$ $>0.05)$. However, the control group showed no differences $(P>0.05)$ between weeks. It is important to point out that in both groups, the progesterone and estradiol concentrations were basal (near zero) in the first week after the beginning of lactation, thus, demonstrating the safety of milk produced (with absence of residues) from that moment onward.

In the fourth week, there was a tendency $(P=$ $0.06)$ for higher levels of progesterone in the induced heifers (Induced Group $=1.07 \pm 0.23 \mathrm{ng} / \mathrm{mL}$ and Control Group $=0.38 \pm 0.28 \mathrm{ng} / \mathrm{mL}$ ). This shows a potentially higher luteinic activity in Induced heifers, where $42 \%$ of the animals showed progesterone concentrations above $1 \mathrm{ng} / \mathrm{mL}$, while just $12.5 \%$ of the Control heifers did. Estradiol concentrations did not differ $(P=0.13)$ between the groups, where Induced $(220 \pm 1.62 \mathrm{pg} / \mathrm{mL})$ and Control $(180 \pm 2.05 \mathrm{pg} / \mathrm{mL})$ heifers were similar. 
At approximately 42 days of lactation (voluntary waiting period of the farm), 33 heifers (Control Group, $n$ $=13$ and Induction Group, $\mathrm{n}=20$ ) were considered suitable for reproduction and were inseminated according to the protocol described previously. The overall pregnancy rate was $47.75 \%$, where Induced heifers showed a preg-

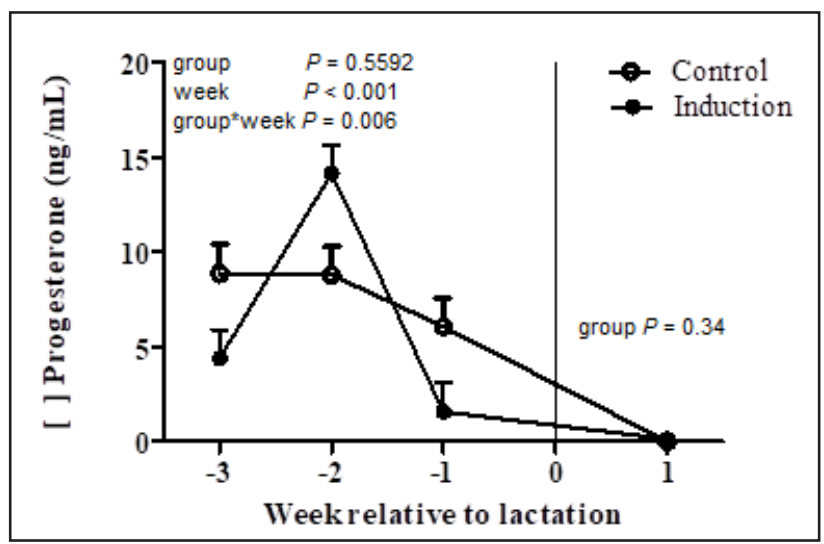

Figure 2. Concentrations of progesterone for control and induced heifers during pre-lactation (weeks $-3,-2$ and -1) and post-lactation (week 1). nancy rate of $40 \%$ and $55.55 \%$ for Control heifers. In relation to all of animals, included that were subject to the conventional reproductive management of the farm, demonstrating the parturition-to-conception interval, the groups did not show statistical differences $(P>0.05)$ [Figure 4], based on data until 224 DIM.

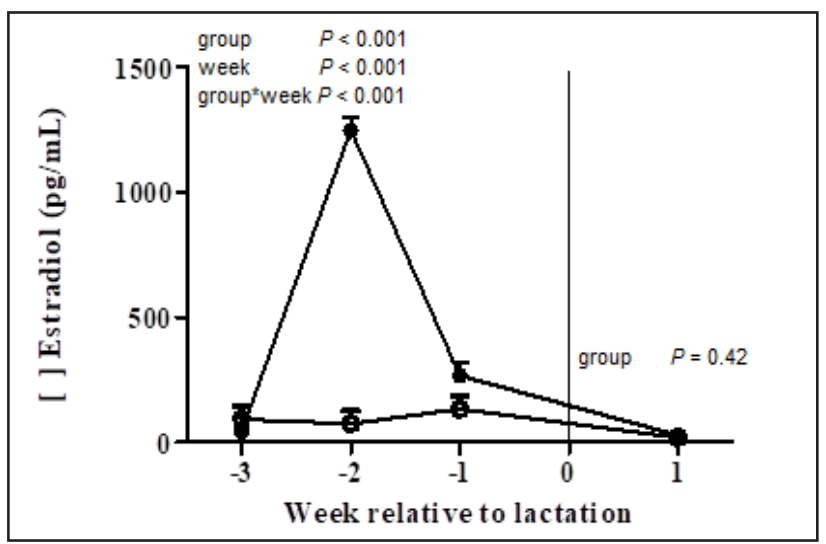

Figure 3. Concentrations of estradiol for control and induced heifers during pre-lactation (weeks $-3,-2$ and -1) and post-lactation (week 1).

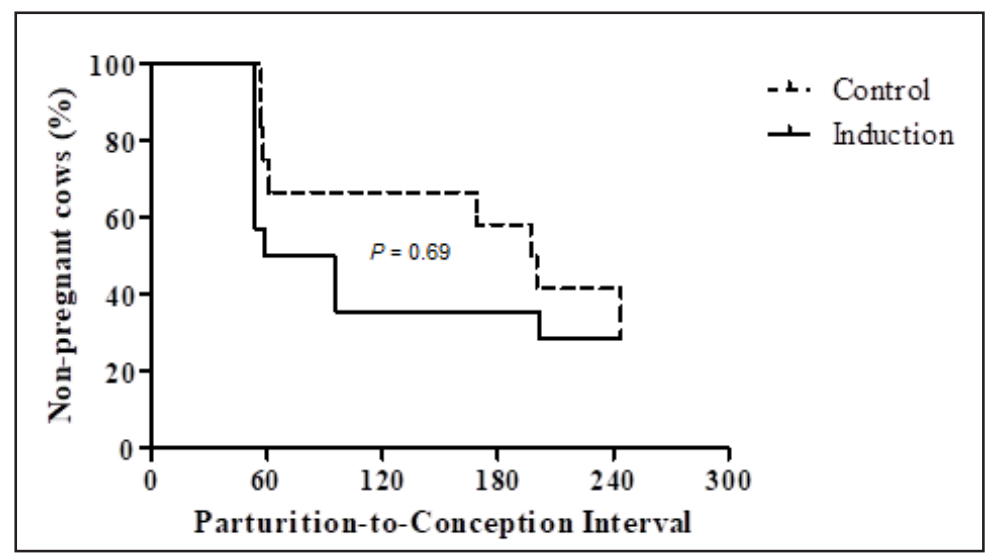

Figure 4. Survival curve of parturition-to-conception intervals of heifers induced (Induction group) and primiparous (Control group) from the beginning of lactation.

\section{DISCUSSION}

The peak of progesterone observed in induced heifers during the pre-lactation was expected, once during the first seven days of the protocol they received progesterone daily, indicating a cumulative accumulation, and as it is known that the hormone utilized (Singrogest $\left.{ }^{\circledR}\right)$, is a long-acting formulation. For Control heifers, progesterone concentrations were elevated due to pregnancy, and then declined markedly towards parturition [2]. Concurrently it is known that there is an increase in prolactin, while estrogen concentrations continued to increase, which are physiological mechanisms to enhance lactation [10].
The differences among groups found during the pre-lactation in concentrations of estradiol corresponds with the daily applications within the protocol. These results suggest that the recommended doses used in this protocol could be re-adjusted by using a lower estradiol dose and a longer period of application. Furthermore, the isolated applications of estradiol can cause intense estrus manifestations when progesterone is not part of the protocol (in our study, we use a long-acting progesterone). Estrus signs are undesirable as they can cause trauma in induced animals. In our study, only 3/30 induced heifers showed estrus during 
the protocol. Physiologically, during the final period of gestation, there is an increase in plasma concentrations of estradiol, which decrease immediately after the parturition [2].

The hormonal dynamics, with progesterone reduction and estradiol increases that occur in this final period of gestation, is essential to trigger the events of mammogenesis and lactogenesis. It is well established that the estrogens stimulate the growth of mammary ducts and that the combination of progesterone and estrogens lead to a synergistic action, stimulating the lobe-alveolar development of the mammary gland. In addition to these hormones, the secretion of prolactin and $\mathrm{GH}$ by the anterior pituitary is also important [5].

Progesterone and estradiol evaluations performed in the first week after the beginning of lactation we intended to evaluate the metabolism and physiological concentration of the hormones used during the protocol. On the other hand, measurements performed in the fourth week were to evaluate the return to cyclicity of the heifers in both groups. Studies evaluating the return to cyclicity have considered animals with progesterone concentrations above $1 \mathrm{ng} / \mathrm{mL}$ to be cyclic, while in our study the animals in the Control group still did not demonstrate luteal activity.

As previously described by other authors [6], during the second week of lactation, 16/30 (53.33\%) of Induced heifers had follicular cysts. Cysts are normally caused by hypothalamic failures in response to estradiol and progesterone [9]. The high hormone doses used in Induced heifers could cause failures in the sensibility and feedback of the hypothalamicpituitary-gonadal axis.

The overall pregnancy rate showed in our results were similar to those of Freitas et al. [3] in re- peated breeder cows, where 29 cows were inseminated after the induced lactation protocol, of which $41.1 \%$ became pregnant. It should be pointed out that $40 \%$ of Induced heifers become pregnant with only one insemination, supporting the finding of previous studies, which suggests a positive effect of induced lactation on fertility. It is possible that the high serum concentrations of estradiol during pre-lactation have interfered in the uterine environment and follicular population of these animals [8]. Furthermore, it is possible that the hormonal combination used has a central effect on the synthesis and release of gonadotrophins and/or an effect on the ovarian follicular population.

\section{CONCLUSIONS}

Based on the hormonal profile evaluated, particularly the endocrine profile, and the reproductive performance of heifers, the results suggest that the protocol for induced lactation has a positive effect on fertility.

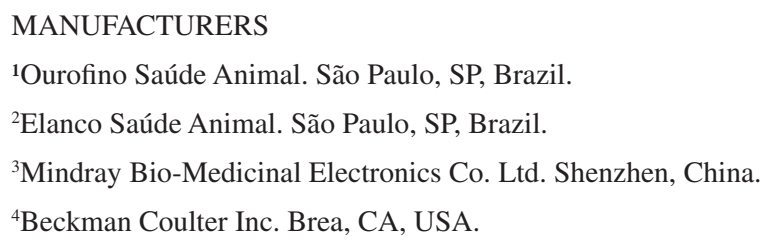

${ }^{1}$ Ourofino Saúde Animal. São Paulo, SP, Brazil.

2Elanco Saúde Animal. São Paulo, SP, Brazil.

${ }^{3}$ Mindray Bio-Medicinal Electronics Co. Ltd. Shenzhen, China.

${ }^{4}$ Beckman Coulter Inc. Brea, CA, USA.

Acknowledgments. To the Núcleo de Pesquisa, Ensino e Extensão em Pecuária (NUPEEC) and Granjas 4 Irmãos S.A. for providing the database. To the $\mathrm{CNPq}$ for financial support (Chamada Universal MCTIC/CNPq 2018).

Ethical approval. All procedures involving animals in the study were approved by the University of Pelotas Animal Care and Use Committee and by the University of Pelotas Research Committee (CEEA 8716-2016).

Declaration of interest. The authors report no conflicts of interest. The authors are responsible for the content and writing of the paper.

\section{REFERENCES}

1 Butler W.R. 2003. Energy balance relationships with follicular development, ovulation and fertility in postpartum dairy cows. Livestock Production Science. 83(2-3): 211-218.

2 Chew B.P., Erb R.E., Fessler J.F., Callahan C.J. \& Malven P.V. 1979. Effects of ovariectomy during pregnancy and of prematurely induced parturition on progesterone, estrogens, and calving traits. Journal of Dairy Science. 62(4): 557-566.

3 Freitas P.R.C., Coelho S.G., Rabelo E., Lana Â.M.Q., Artunduaga M.A.T. \& Saturnino H.M. 2010. Artificial induction of lactation in cattle. Revista Brasileira de Zootecnia. 39(10): 2268-2272.

4 LeBlanc S.J. 2012. Interactions of Metabolism, Inflammation, and Reproductive Tract Health in the Postpartum Period in Dairy Cattle. 2012. Reproduction in Domestic Animals. 47(5): 18-30.

5 Lyons W.R. 1958. Hormonal synergism in mammary gland growth. Proceedings of the Royal Society. 149: 303-325. 
6 Mellado M., Nazarre E., Olivares L., Pastor F. \& Estrada A. 2006. Milk production and reproductive perfomance of cows induced into lactation and treated with bovine somatotropin. Animal Science. 82(4): 555-559.

7 Pritchard T., Coffey M., Mrode R. \& Wall E. 2013. Genetic parameters for productive, health, fertility and longevity traits in dairy cows. Animal Journal. 7(1): 34-46.

8 Sawyer G., Fulkerson W., Martin G. \& Gow C. 1986. Artificial induction of lactation in cattle: initiation of lactation and estrogen and progesterone concentrations in milk. Journal of Dairy Science. 69: 1536-1544.

9 Silvia W.J., Hatler T.B., Nugent A.M. \& Laranja da Fonseca L.F. 2002. Ovarian follicular cysts in dairy cows: an abnormality in folliculogenesis. Domestic Animal Endocrinology. 23: 167-177.

10 Smith K.L. \& Schanbacher F.L. 1973. Hormone induced lactation in bovine. I. lactation following injections of 17ß-estradiol and progesterone. Journal of Dairy Science. 56(6): 738-743. 